\title{
Mimesis y deseo en la novela realista decimonónica: La Regenta de Leopoldo Alas, "Clarín" (Segunda parte)
}

Mimesis and desire in the 19th century realist novel: La Regenta by Leopoldo Alas, "Clarín" (Part two)

\section{Edson Faúndez V.}

Universidad de Concepción. Concepción, Chile

efaundez@udec.cl

\section{RESUMEN}

Leopoldo Alas construye, en La Regenta, un mundo regido por "el gusano maldito, del amor de los sentidos". El examen de la dimensión deseante de la novela invita a reflexionar, entre otros aspectos, sobre los sentidos de la perversión y la monstruosidad.

Palabras clave: Literatura española, perversión, monstruosidad.

\section{ABSTRACT}

Leopoldo Alas, in La Regenta, constructs a world ruled by "the damned worm, of the love of the senses". A look at the dimension of desire in the novel is an invitation to reflect on, among other aspects, the meanings of perversion and monstrosity.

Keywords: Spanish literature, perversion, monstrosity.

Recibido: 24.03.2012. Aceptado: 18.10.2012.

*Artículo escrito dentro del marco del Proyecto FONDECYT de Iniciación en Investigación № 11075025, titulado "Mimesis y deseo en la novela realista decimonónica: La Regenta de Leopoldo Alas, 'Clarín”'. La primera parte de esta investigación fue publicada en Acta Literaria, 40, 109-132. 


\section{EL “GUSANO MALDITO, DEL AMOR DE LOS SENTIDOS”}

M aría del Carmen Bobes Naves (1993: 81-83) afirma que fundamentalmente son cuatro las causas que los comentaristas de la novela $\mathrm{La}$ Regenta de Leopoldo Alas han utilizado para explicar el carácter "inestable", "inmaduro" e "impresionable" de la Regenta: a) Ana se encuentra insatisfecha en su matrimonio y quiere en su inconsciente un amor completo, b) Ana se enamora apasionadamente de don Álvaro, c) Ana, desengañada de la religión, se siente atraída por inclinaciones sensuales, d) Ana necesita afecto y lo encuentra en un amante. La aparente dificultad para establecer el relato del origen de Ana Ozores con la información que surge de las perspectivas del narrador, de los personajes, de los acontecimientos y del lector implícito, permite pensar en el carácter abierto del personaje y sugerir que la causa de la inestabilidad de Ana Ozores se mantiene como uno más de los lugares vacíos del relato ${ }^{1}$. La proliferación de lecturas sobre la génesis del carácter de la protagonista de la novela confirma lo anterior. Los comentarios críticos de Gullón y Vilanova, por ejemplo, proponen que La Regenta es el relato de una mujer que "se deja seducir por el presuntuoso Mesía [debido a su] falta de densidad moral" (Gullón, 1954: 176) y "una versión naturalista de la caída de una mujer buena, degenerada por el conflicto insoluble entre la represión de sus instintos actuales y el cumplimiento de sus deseos morales" (Vilanova, 2001: 158-159). ¿Pero qué es aquello que se encuentra cifrado en el oscuro nacimiento del "personaje de la tentación" por excelencia de la novela? Tal vez la determinación y examen de la posición de deseo inmanente al nacimiento de Ana Ozores pueda producir la fábula del origen de uno de los personajes más estudiados de la novela de Leopoldo Alas.

Ana Ozores es un personaje construido sobre la base de una unión inconcebible para la organización del entramado social vetustense: un noble y una plebeya. El amor pasión que empuja al librepensador, liberal y revolucionario Carlos Ozores a contraer matrimonio "a los treinta y cinco años con una humilde modista italiana que vivía en medio de seducciones sin cuento, honrada y pobre" (Alas, 1900, I: 98) pone en riesgo las ficciones de homogeneidad e identidad dominantes. El desorden que conllevan la mezcla de heterogéneos (el noble y la plebeya) y la visibilidad pública de esta "alianza nefasta" (el matrimonio) sólo puede ser considerado como abominable por la moral hegemónica:

${ }^{1}$ En otro artículo, titulado "Realismo e indeterminación (Aproximación teórico-crítica). El caso de La Regenta de Leopoldo Alas, 'Clarín”" (Faúndez, 2012a), examino, siguiendo a Wolfgang Iser, la presencia de lugares vacíos y negaciones en la novela de Alas. 
-Abominable -añadió Glocester, inclinándose-. Representa una alianza nefasta en que la sangre, a todas luces azul de los Ozores, se mezcló en mala hora con sangre plebeya; y lo que es peor..., según todos sabemos, representa esa niña la poco meticulosa moralidad de su madre (Alas, 1900, I: 130$)$.

El discurso de Glocester puede ser relacionado con las proposiciones teóricas del "degeneracionismo" francés, muy influyentes en España a fines del siglo XIX ${ }^{2}$. Es interesante poner en relación las palabras de Glocester con las de C. O. Bunge, autor de La educación de los degenerados. Teoría de la educación: "los cruces continuos de gérmenes sanos y gérmenes debilitados por la herencia dan, por consecuencia, el alarmante incremento de las anomalías de la especie, o sea, no ya la degeneración individual o parcial, sino la degeneración total o social" (1903: 75). Ana Ozores, desde la perspectiva de Glocester, representa la degeneración de una casta privilegiada, pero también la inconcebible posibilidad de "la degeneración total o social". La actualización del cruce proscrito revela, entre otros problemas, el miedo al deseo, que se encuentra presente en la novela realista española y de manera ejemplar en la relación incestuosa de Perucho y Manolita narrada en el capítulo XXI de La madre naturaleza de Emilia Pardo Bazán (1887). El relato del origen de Ana Ozores se vincula con el surgimiento de la figura del monstruo, en el sentido propuesto por Michel Foucault en Los anormales (2000: 61), a saber, el monstruo es esencialmente una noción jurídica que se utiliza para señalar una doble violación: de las leyes de la sociedad y de la naturaleza. El monstruo, por otra parte, es un fenómeno extremo y raro, la excepción y el punto de derrumbe de la ley, el que transforma lo imposible y lo prohibido.

Ana es legataria de la violación a las leyes de la sociedad que desencadena la alianza de sus padres. Michel Nimetz advierte por ello que uno de los rasgos singularizadores de La Regenta es la crueldad: "Clarín maneja el látigo muy a gusto. Lo que hace de La Regenta una novela experimental cruel, es que él graba los pecados de los padres en la carne de los hijos. Ya que el hombre todo lo corrompe, su propagación es maligna” (1971: 252). La monstruosidad de la Regenta pareciera residir, entonces, en la dimensión de los pecados de la carne. Estos la convertirán en "un fenómeno a la vez extremo y extremadamente raro. [En] el límite, el punto de derrumbe de

\footnotetext{
${ }^{2}$ Vázquez García y Moreno Mengíbar, en Sexo y razón. Una genealogía de la moral sexual en España (siglos XVI-XX), escriben: “el 'degeneracionismo' francés (Magnan, Morel, Lucas, Robot), orientación teórica sumamente influyente en España desde finales del siglo XIX, que decae en importancia a partir de 1910 aproximadamente" (1997: 160).
} 
la ley" (Foucault, 2000: 61): víctima sacrificial de un universo regido por la desmedida proliferación de las formas del $\mathrm{mal}^{3}$. El problema, con todo, es más complejo aún. Ana es "el punto de derrumbe de la ley" secreta que gobierna en Vetusta: la lujuria. El devenir en monstruo de Ana no se explica únicamente por su condición de cuerpo saturado de deseo sexual, pues la norma indica que en todos los personajes ocurre lo mismo, sino fundamentalmente por su resistencia a aceptar el relato de su origen y entregarse a la secreta y oscura ley de la carne que rige el espacio novelesco. La castidad de Ana cifra así una diferencia intolerable. El proyecto de Álvaro Mesía, desde este acceso, es también el proyecto de Vetusta: acorralar, capturar, devorar a la Regenta. La disolución de la verdad (castidad y fidelidad conyugal) de Ana, la reducción de la diferencia y la homogeneización en el vicio: materia de la novela de Clarín.

El narrador de la novela realista -al igual que el lector- se encuentra fascinado por un personaje con las características de Ana Ozores. No puede resistir el placer de ver y narrar la intimidad de un personaje cuya monstruosidad se construirá sobre la base de la mezcla de "sangre azul" y "sangre plebeya” y del adulterio. La niña, que se convertirá en la imagen más noble de Vetusta y en el personaje asediado por los poderes infernales, es heredera del "tráfico indigno" de la carne. Ese es el saber escandaloso que irrumpe en el episodio en que la fantasía de Ana, contagiada del mito del héroe que descubre en la lectura de los poemas épicos Ilíada y Ramayama, la hace desear emprender aventuras peligrosas junto a Germán, el niño de Colondres. El deseo mediatizado por la epopeya edifica los mundos que le permiten a la niña fugarse del control severo de doña Camila, invitando a Germán a una "escapatoria nocturna para ver juntos la luna desde la barca y contarse cuentos" (Alas, 1900, I: 106). Las aventuras de los niños son comprendidas por doña Camila e Iriarte, como advierte el narrador, de modo grosero y lascivo:

Ya se sabe cómo entendió la grosera y lasciva doña Camila la aventura de los niños. Era de tal índole la maldad de esta hembra, que daba por buenas las desazones que el lance pudiera causarle, por la responsabilidad que ella tenía, con tal de ver comprobados por los hechos sus pronósticos.

$-<<$ Como su madre! -decía a las personas de confianza-. ¡Improper im-

${ }^{3}$ En "La Regenta: Literatura y mal" (Faúndez, 2012b) he examinado la relación profunda que la novelística de Alas establece con el mal. 
proper! ¡Si ya lo decía yo! El instinto..., la sangre... No basta la educación contra la naturaleza.>>

[...] Camila refería la aventura a quien la quisiera oír, llorando la infeliz, rendida bajo el peso de la responsabilidad (y ella poco podía contra la naturaleza), el escándalo corrió de boca en boca, y hasta en el casino se supo lo de aquella confesión a que se obligó a la reo. Se discutió el caso fisiológicamente. Se formaron partidos; unos decían que podía ser, y se citaban multitud de ejemplos de precocidad semejante.

-Créanlo ustedes - decía el amante de doña Camila-, el hombre nace naturalmente malo, y la mujer lo mismo.

Otros negaban la verosimilitud de los hechos cuando menos.

-Si ponen ustedes eso en un libro, nadie lo creerá.

Ana fue objeto de curiosidad general. Querían verla, desmenuzar sus gestos, sus movimientos para ver si se le conocía en algo.

-Lo que es desarrollada, lo está, y mucho, para su edad... decía el hombre de doña Camila, que saboreaba por adelantado la lujuria de lo porvenir.

-En efecto, parece una mujercita.

Y se la devoraba con los ojos; se deseaba un milagroso crecimiento instantáneo de aquellos encantos que no estaban en la niña, sino en la imaginación de los socios del casino (1900, I: 106-107).

La maldad de doña Camila y su lujurioso amante producen un discurso que llena de sexo el cuerpo de la niña. El proceso retórico de construcción del otro, en este caso, recurre a la historia del nacimiento - “`Cómo su madre!"- para crear el rostro monstruoso e incorregible de Ana Ozores. La relación de poder presente en el episodio que "condena definitivamente a Ana” (Coletes Blanco, 2002: 50) revela, en primer lugar, que Camila y su amante son, en realidad, los verdaderos cuerpos saturados de sexo; por otro lado, el ejercicio del poder, mediante el cual se produce la verdad del otro, genera placer. Placer de hablar sobre el cuerpo y el sexo... Placer de fabular las formas maduras y desnudas del cuerpo de la niña que soñó junto al niño 
de Colondres heroicas aventuras.

La reunión de los contrarios, el descontrol del deseo y la transgresión del orden inmanente al relato del origen de Ana son signos que dibujan una herencia maligna. Sabemos que las dos causas evidentes de regulación de la diferencia heredada son la belleza física, que permite cubrir la ignominia del origen, y el matrimonio con Víctor Quintanar, que permite la liberación de sus pérfidas tías y consolidar su posición y prestigio sociales. El olvido del oscuro nacimiento de Ana y de la aventura de la barca es, con todo, aparente. La consagración de Ana "al sacrificio, a una prohibición absoluta del placer" (Alas, 1900, I: 278), si bien cifra la resistencia a la ley de la carne que gobierna Vetusta ${ }^{4}$, advertida con inusual asombro por la "chusma" en el paseo de Ana y Petra por la "calle del triunfo de 1836 ", no exorciza al monstruo sexual (creado por Glocester, doña Camila e Iriarte), que la propia Ana percibe en el episodio de la procesión ${ }^{6}$.

El matrimonio, que nos advierte sobre la pervivencia de las uniones criticadas en El si de las niñas de Leandro Fernández de Moratín ${ }^{7}$, la prohibición del placer y la juventud que huye son los alicientes, según Vilanova, del despliegue del "ansia de placer sensual y de goce puramente físico que la protagonista confunde con una gran pasión” (2001: 177). Olvida Vilanova que en el estallido del deseo influyen también las lecturas que Ana ha realizado y la proximidad con mujeres como Visita y Petra: verdaderas mediaciones (externas e internas) del deseo ${ }^{8}$ que empujan a Ana cada vez con más intensidad hacia Álvaro Mesía. ¿Es la Regenta, sin embargo, un personaje al que, examinado a la luz de la familia "no como potencia de prohibición, sino factor capital de sexualización” (Foucault, 2007: 139), se le ha negado

\footnotetext{
${ }^{4}$ Michael Nimetz escribe: "en La Regenta, la castidad es la mayor virtud, excepto cuando es refugio para los temores sexuales (como en el caso de Bermúdez). De no ser así, es la condición humana ejemplar la relación ideal entre personas es la de hombre-naturaleza (el joven Fermín y sus montañas; Frígilis y sus plantas)" (1971: 251).

${ }^{5}$ En el capítulo IX de la primera parte, se lee: "los grupos se abrían para dejar paso a la Regenta. Los mozalbetes más osados acercaban a ellos el rostro con cierta insolencia, pero la belleza bondadosa de aquella cara de María Santísima les imponía admiración y respeto" (Alas, 1900, I: 277).

6 "Aquellos pies desnudos eran para ella la desnudez de todo el cuerpo y de toda el alma. $i<<$ Ella era una loca que había caído en una especie de prostitución singular; no sabía por qué, pero pensaba que después de aquel paseo a la vergüenza ya no había honor en su casa. Allí iba la tonta, la literata, Jorge Sandio, la mística, la fatua, la loca, la loca sinvergüenza>>" (Alas, 1900 II: 395).

${ }^{7}$ Téngase presente que, al decir de Foucault, "la familia es el cambiador de la sexualidad y de la alianza: trasporta la ley y la dimensión de lo jurídico hasta el dispositivo de sexualidad; y trasporta la economía del placer y la intensidad de las sensaciones hasta el régimen de la alianza” (Foucault 2007: 132).
}

${ }^{8}$ Sigo, en este punto, las proposiciones de René Girard (1963). 
la posibilidad de placer? Sabemos que Ana descubre los placeres de la lectura y de la imaginación, cuando aún es una niña. La aventura de la barca es de hecho una experiencia que sintetiza ambas instancias. Suprimido el goce que suscita el encuentro sexual de los cuerpos, en "la alianza descarriada" del matrimonio, Ana obtendrá placer y satisfacción sexual a partir de los sueños, lo que satura de deseo el espacio de la familia. Antonio Vilanova escribe:

Si los ensueños lascivos de Anita Ozores, protagonizados por la apuesta figura de don Álvaro Mesía, revelan claramente el secreto amor que le profesa y la intensidad del deseo sensual y físico que siente por él, la evidente satisfacción erótica que le produce soñar todas las noches con el hombre a quien ama explica que, a pesar de su frustración y su amargura, pueda mantener una castidad ejemplar al margen del sexo y de la carne. Es evidente, en efecto, que la falta de relaciones íntimas con don Víctor y la ausencia de una vida sexual normal en el seno del matrimonio han llevado a la Regenta a identificar la satisfacción sexual con el goce ilusorio que la imaginación le procura durante el sueño. $\mathrm{Y}$, al propio tiempo, le ha permitido hacer compatible el pecado de pensamiento, gracias al cual le es posible satisfacer engañosamente la pasión que la consume, con la más estricta fidelidad conyugal, totalmente al margen de la intimidad física con otro hombre (Vilanova, 2001: 171).

El desacuerdo entre los medios del placer deseado y el placer obtenido es otra de las figuraciones que adopta la tensión entre los deseos románticos de los personajes femeninos y la realidad textualizada en las novelas realistas decimonónicas. Dicha incompatibilidad es, por ejemplo, la que sumerge a Emma Bovary y Ana Ozores, los dos personajes femeninos que se encumbran como figuras paradigmáticas de la novela realista, en el ennui (tedio), que involucra una mirada y una lectura negativas del mundo, y, como correlato, el autoexilio y la búsqueda incesante de experiencias que subviertan el tedio generado por el orden burgués. Sonia Núñez Puente señala:

El individuo afectado por el ennui queda estigmatizado e imbricado en su nueva condición de paria, lo que revela una configuración que comienza a producir en la segunda mitad del siglo XIX un nuevo tipo literario: el de la mujer exiliada de la sociedad burguesa, atrincherada en el espacio social en el que, gracias a la expulsión provocada por el tedio, inicia la gestación de un nueva desorden pulsional paralelo y, a un tiempo, ajeno al sistema del orden pasional burgués (2001: 20). 
La novela realista revela, sin embargo, que dicho "desorden pulsional" no es propiedad de un personaje en particular ni es "ajeno al sistema del orden pasional burgués". Jean-François Botrel, de hecho, propone que La Regenta puede ser utilizada para construir "una socioantropología histórica del sexo, del eros de la restauración” (1992: 109).

La posición de deseo que singulariza el nacimiento de Ana Ozores desnuda, pues, la ilusión de estabilidad que gobierna una sociedad que pretende "codificar los flujos del deseo, inscribirlos, registrarlos, lograr que ningún flujo fluya si no está canalizado, taponado, regulado" (Deleuze y Guattari, 1995: 39). El matrimonio desigual de sus padres constituye un obstáculo para la inscripción, registro y regulación del deseo. La transgresión del dispositivo matrimonial y de las nociones de identidad, sistema y orden traen como consecuencia la sanción y expulsión sociales de Carlos y la modista italiana. La (imposible) autorización social de esta "alianza nefasta" devuelve la posición de deseo a las sombras y el secreto desde donde nunca debió salir. La diferencia de la cual Ana Ozores es heredera, sin embargo, parece resistir todo. La expulsión o regulación de la diferencia -muerte temprana de la madre y regulación por la belleza, el matrimonio y la renuncia involuntaria al placer carnal- es efectiva, pero al mismo tiempo se convierte en una ilusión que gobierna aparentemente la ciudad. La admiración, respeto y envidia que suscita la Regenta nada pareciera decir sobre la condición de extranjera o paria que intensifica el estigma monstruoso que ha recibido desde su nacimiento. El despliegue de la imaginación y las ensoñaciones de la carne revela que el control absoluto de los placeres es pura ilusión. La renuncia de Ana a los sentidos y a los placeres es una quimera producida por la regulación social de la diferencia. La verdad del deseo de la novela se elucida, por lo tanto, en la indestructibilidad de los deseos y los placeres, y, en consecuencia, en el fracaso de los dispositivos y las estrategias encargados de su control. Doña Camila lo explicita cuando aún Ana es una niña; el narrador, cuando Ana irremediablemente se encamina hacia Álvaro Mesía: "desde entonces educó a la niña sin esperanzas de salvarla, como si cultivara una flor podrida ya por la mordedura de un gusano" (Alas, 1900, I: 107), "porque ella estaba tocada del gusano maldito, del amor de los sentidos” (Alas, 1900, II: 359).

\section{"PINCHAZOS DE LA CARNE"}

La crítica ha mostrado cómo mediante sugerencias y metáforas La Regenta introduce el cuerpo y el placer en la novela realista. Jean-François Botrel 
(1992), por ejemplo, considera escenas de saturación erótica las relaciones entre Teresina y el Magistral (Capítulo XXI) y el botón de rosa (Capítulo XXI). Andrés Zamora Juárez, advierte, comentando las reflexiones de Noël Valis, que "la escritura realista es gula y, por ende, lujuria" (1999: 135)". John Kronik sugiere que Celedonio, doble de don Fermín, cifra la inclusión del cuerpo, el deseo y el mal en la medida en que se vincula con la figura del sapo: "desfigurado en su sotana sucia y raída, se pasa el tiempo escupiendo sobre los transeúntes. En un toque lingüístico plenamente grotesco, el narrador le echa el epíteto irónico de 'caballero'. He aquí ya, en la segunda página del texto, el sapo -escupiendo, viscoso, asqueroso- con quien se cerrará la novela" (1987: 521). Zamora Juárez agrega: "finalmente, hay que insistir, la capacidad de penetrar, poseer, crear y dominar personajes tiene claras connotaciones sexuales" (1999: 162). Antonio Vilanova, por su parte, señala: "Ana sentía un placer puramente material, pensaba ella, en aquel sitio de sus entrañas que no era el vientre ni el corazón, sino en el medio. Sí, el placer era puramente material, pero su intensidad le hacía grandioso, sublime" (2001: 186). La tríada deseo, cuerpo y placer recorre las formas de expresión y de contenido en la novela de Clarín. John Rutherford señala por ello que "entre los novelistas decimonónicos que dan cuenta más cabal de la importancia de lo fisiológico (y no me limito a España) está Clarín” (1988: 80) $)^{10}$.

El "gusano maldito, del amor de los sentidos" es indestructible en la novela de Alas. El novelista español sabe que ese "gusano" pervive en las zonas oscuras de la sociedad y que su capacidad de propagación y contagio no puede ser detenida con las estrategias de las disciplinas y regulaciones sociales. Iluminar las zonas oscuras, narrar lo inconfesable, producir la verdad de los placeres del perverso. Esos son los signos distintivos de la escritura de Alas que coinciden con los mitos del poder disciplinario: iluminarlo todo, registrarlo todo, escribirlo todo. Sería un error por ello localizar en un personaje específico los "indestructibles" e ingobernables deseos perturbadores. Todos los personajes de la novela están dominados por los mismos deseos que dibujan la monstruosidad de Ana Ozores. El rostro monstruoso de Ana

${ }^{9}$ La escena del botón de rosa del capítulo XXI es ejemplar en lo que se refiere a las relaciones entre gula y lujuria. Del mismo modo puede ser leída la escena de Obdulia y Pedro o el diálogo de Visita y Álvaro con el que concluye el capítulo VIII de la primera parte.

${ }^{10}$ En el artículo "Mimesis y deseo en la novela realista decimonónica: La Regenta de Leopoldo Alas, "Clarín" (Primera parte)" (Faúndez, 2010), analizo dos problemas fundamentales de la novela: la escritura como espacio de la confesión y como cuerpo saturado de sexo. El diálogo con la crítica precedente aborda las proposiciones de Sergio Beser (1982), por lo que no las he considerado en este artículo. 
es, en realidad, una construcción discursiva de una sociedad que intenta (inútilmente) exorcizar su propio desorden interior. El "gusano maldito, del amor de los sentidos" recorre y devora el universo de Vetusta. Puede leerse así la textualización del secreto inconfesable de "don Saturnino Bermúdez, doctor en teología, en ambos derechos civil y canónico, licenciado en filosofía y letras y bachiller en ciencias":

Era él que salía disfrazado de capa y sombrerito flexible. No había miedo que en tal guisa le reconociera nadie. ¿YY adónde iba? A luchar con la tentación al aire libre; a cansar la carne con paseos interminables; y un poco también a olfatear el vicio, el crimen pensaba él, crimen en que tenía seguridad de no caer, no tanto por esfuerzos de la virtud, como por invencible pujanza del miedo que no le dejaba nunca dar el último y decisivo paso en la carrera del abismo. Al borde llegaba todas las noches, y solía ser una puerta desvencijada, sucia y negra en las sombras de algún callejón inmundo. Alguna vez desde el fondo del susodicho abismo le llamaba la tentación; entonces retrocedía el sabio más pronto, ganaba el terreno perdido, volvía a las calles anchas y respiraba con delicia el aire puro, como su cuerpo, y para llegar antes a las regiones del ideal que eran su propio ambiente, cantaba la Casta diva o el Spirto gentil o el Santo fuerte, y pensaba en sus amores de niño o en alguna heroína de sus novelas [...].

Solía volver a sus novelas de la hora de dormirse la imagen de la Regenta, y entablaba con ella, o con otras damas no menos guapas, diálogos muy sabrosos en que ponía el ingenio femenil en lucha con el serio y varonil ingenio suyo; y entre estos dimes y diretes, en que todo era espiritualismo $y$, a lo sumo, vagas promesas de futuros favores, le iba entrando sueño al arqueólogo, y la lógica se hacía disparatada, y hasta el sentido moral se pervertía y se desplomaba la fortaleza de aquel miedo que poco antes salvara al doctor en teología (Alas, 1900, I: 32-34).

La tentación no es sólo el signo distintivo de Ana Ozores, Fermín de Pas, Álvaro Mesía, Obdulia Fandiño, Paco Vegallana, sino también del autor de "Vetusta romana, Vetusta goda, Vetusta feudal, Vetusta cristiana y Vetusta transformada". El miedo paraliza el deseo que lleva a Bermúdez a "olfatear el vicio, el crimen” en los alrededores de los prostíbulos más miserables de la ciudad. El miedo, sin embargo, no doblega completamente las insinuaciones de la carne, sólo las condena aún más a la invisibilidad y el secreto. La imaginación desbocada, las lecturas románticas -que constituyen, según Gregorio 
Marañón, una verdadera pedagogía negativa ${ }^{11}$ - y el recuerdo de la Regenta hacen posible a "la hora de dormirse" que la aventura de la carne iniciada en su periplo por los callejones inmundos concluya en una forma sustituta de placer. "El sentido moral" y la voluntad del sabio de Vetusta se rinden a los placeres del vicio solitario. El narrador, aunque Bermúdez se oculte, ilumina lo más privado y lo más secreto, consiguiendo hacer visible y legible la verdad oculta del deseo: el onanismo de Bermúdez. La escena de la mollities permite establecer relaciones entre los poderes normalizadores dominantes en el siglo XIX y el cuerpo. La imposibilidad de Bermúdez de controlar las inclinaciones de la carne lo convierten en un sujeto inadaptado, cuya perversidad no sólo lo afecta a él sino también a la colectividad toda. El placer solitario, egoísta y asocial del masturbador ya es considerado en el siglo XVI como peligroso. El siglo XIX lo convertirá, entre otros aspectos, en desencadenante de nuevas perversiones y clave hermenéutica para descifrar las causas de las anomalías adultas. Las técnicas disciplinarias de vigilancia, corrección y construcción de la subjetividad de un individuo útil y dócil a las expectativas del sistema y las técnicas de regulación social (educación sexual) que afectan a la comunidad en su conjunto constituyen las dos estrategias del poder en las sociedades normalizadoras ${ }^{12}$ perturbadas por la perversión de Bermúdez. El acto contranatura es, según los higienistas del siglo XIX ${ }^{13}$, desviación, exceso de imaginación y enfermedad, pero también es un obstáculo para la organización del deseo en la red social, para la economía de amplificación de las energías corporales (utilidad) y para la política de docilidad emprendida por los poderes hegemónicos. Bermúdez, siguiendo la racionalidad sexual del siglo XIX, es un perverso y un enfermo. La perversidad sexual que Alas crea para este personaje es propia de un niño o un adolescente. El secreto revelado por el narrador, además de mostrar la proliferación de deseos perturbadores, produce la infantilización del personaje, lo que constituye uno de los signos con los cuales se dibuja narrativamente su degradación.

${ }^{11}$ Marañón, en Amiel. Un estudio sobre la timidez, señala que en esta pedagogía negativa participan: "los amigos petulantes o pervertidos, los librillos clandestinos, las mismas obras maestras del arte" (1958: 55).

${ }^{12}$ Vázquez García y Moreno Mengíbar señalan: "la integración de los mecanismos disciplinarios y los de regulación biopolítica en torno al problema de la masturbación datan del siglo XVIII, pudiéndose encontrar ya su formulación explícita en la obra de Tissot" (1997: 116).

${ }^{13}$ Vázquez García y Moreno Mengíbar escriben: "los higienistas hasta mediados del siglo XIX, conservarán este concepto de la masturbación como sustituto artificial del coito (desviación de la naturaleza), enfermedad (amenaza a la salud individual y colectiva) y exceso de la imaginación (alteración de los límites de la necesidad)" (1997: 101). 
La irrupción del deseo y el placer no involucra sólo a personajes aislados. El episodio de la misa del gallo es especialmente significativo en lo que respecta a los trabajos del "gusano" de los deseos sexuales en la sociedad vetustense.

Había otra clase de profanaciones que no podía evitar la ronda. Apiñábase el público en el crucero, oprimiéndose unos a otros contra la verja del altar mayor, y la valla del centro, debajo de los púlpitos, y quedaban en el resto de la catedral muy a sus anchas los pocos que preferían la comodidad al calorcillo humano de aquel montón de carne repleta. Como la religión es igual para todos, allí se mezclaban todas las clases, edades y condiciones. Obdulia Fandiño, en pie, oía la misa apoyando su devocionario en la espalda de Pedro, el cocinero de Vegallana, y en la nuca sentía la viuda el aliento de Pepe Ronzal, que no podía, ni tal vez quería, impedir que los de atrás empujasen. Para la de Fandiño, la religión era esto: apretarse, estrujarse sin distinción de clases ni sexos en las grandes solemnidades con que la Iglesia conmemora acontecimientos importantes de que ella, Obdulia, tenía muy confusa idea; Visitación estaba también allí, más cerca de la capilla, con la cabeza metida entre las rejas. Paco Vegallana, cerca de Visitación, fingía resistir la fuerza anónima que le arrojaba, como un oleaje, sobre su prima Edelmira. La joven, roja como una cereza, con los ojos en un San José de su devocionario y el alma en los movimientos de su primo, procuraba huir de la valla del centro contra la cual amenazaban aplastarla aquellas olas humanas, que allí en lo oscuro imitaban las del mar batiendo un peñasco en la negrura de su sombra. Todo el elemento joven de que hablaba El Lábaro en sus crónicas del pequeñísimo gran mundo de Vetusta estaba allí, en el crucero de la catedral, oyendo como entre sueños el órgano, dirigiendo la colación de Nochebuena, viendo lucecillas, sintiendo entre temblores de la pereza pinchazos de la carne. El sueño traía impíos disparates, ideas que eran profanaciones, y se desechaban para atenerse a los pecados veniales con que brindaba la realidad ambiente. Miradas y sonrisas, si la distancia no consentía otra cosa, iban y venían enfilándose como podían en aquella selva espesa de cabezas humanas. Se tosía mucho y no todas las toses eran ingenuas. En aquella quietud soporífera, en aquella oscuridad de pesadilla, hubieran permanecido aquellos caballeritos y aquellas señoritas hasta el amanecer, de buen grado. Obdulia pensaba, aunque es claro que no lo decía sino en el seno de la mayor confianza, pensaba que el hacer el oso, que era a lo que llamaba timarse Joaquín Orgaz, si siempre era agradable, lo era mucho más en la Iglesia, porque allí 
tenía un cachet. Y para la viuda las cosas con cachet eran las mejores (Alas, 1900: 293-294).

¿De qué clase son "las profanaciones" que no puede evitar la ronda en la escena de la misa del gallo? ¿Qué es aquello que en la novela de Alas pareciera resistir el control social de los deseos? ${ }^{14}$. Son las mismas inclinaciones de la carne que irrumpen en la imaginación de la lasciva doña Camila o que derrumban las barreras morales de Saturno Bermúdez, las que se apoderan de uno de los acontecimientos espirituales más significativos del catolicismo de Vetusta. El triunfo de la carne explicita la derrota momentánea de la espiritualidad religiosa, a la vez que el fracaso de la ilusión axial de la modernidad: el control del deseo mediante la producción de la subjetividad del individuo en el contexto de la ciudad. La tensión que apenas contiene la Iglesia de Vetusta se establece entre el poder, que opera sobre los cuerpos individual y colectivo, y el deseo que libera los flujos reprimidos. Dicha tensión se encuentra cifrada en la figura de Obdulia Fandiño y sus dos secretos amantes, Pedro y Pepe Ronzal. El libro, el devocionario, se encuentra apoyado en la espalda, el cuerpo, de Pedro. En esa guerra silenciosa pareciera vencer, por ahora, el cuerpo. Los cuerpos saturados de erotismo ${ }^{15}$ que participan en la Misa del Gallo dejan de ser cuerpos de individuos disciplinados para constituirse en un puro cuerpo colectivo y deseante que evidencia la supremacía de lo instintivo-salvaje por sobre lo racional-civilizado: los cuerpos "oprimiéndose unos a otros" se convierten en "un montón de carne repleta", en "una selva espesa de cabezas humanas". La sociedad vetustense enseña así sus inconfesables pasiones subterráneas. Todas las "clases, edades y condiciones" se mezclan de manera obscena en una escena que puede ser leída con acierto utilizando las proposiciones teóricas del carnaval de Bajtin (1990); lo escandaloso, sin embargo, aquí no es la fiesta. Lo escandaloso es el deseo que roe por debajo el sentido mismo de la ceremonia religiosa. La Fandiño, quien es "un escándalo andando", conoce lo que el narrador permite que el lector descubra al iluminar el secreto de los cuerpos en la (lúbrica) reunión espiritual: "la religión era esto: apretarse, estrujarse sin distinción de clases ni sexos". La mezcla de edades, estados, jerarquías, parentescos sella la irrupción de los "pinchazos de la carne". Su presencia despliega una escritura que

${ }^{14}$ Michael Nimetz, en "Eros e Iglesia en la Vetusta de Clarín", advierte sobre la importancia del perturbador encuentro entre sexo y religión: "la perversión, en su sentido más amplio, es el resultado de este dispar abrazo entre sexo y religión" (1971: 243).

${ }^{15}$ Jean-François Botrel (1992: 109-128) considera que la novela de Alas está saturada de erotismo. 
se actualiza en el cuerpo mismo de los personajes. Edelmira, la joven prima de Paco Vegallana, está "roja como cereza". El narrador se detiene en un detalle del rostro de Edelmira para sugerir la manifestación del deseo. Del mismo modo, puede ser leído el episodio de los amores de Petra y su primo Antonio: "llegó Petra. Venía sudando, muy encarnada, con la respiración fatigosa. Le caían hasta los ojos los rizos dorados y menudos. Como había visto tan ensimismada a la señora, se había llegado al molino de su primo Antonio, que estaba allí cerca, a un tiro de fusil" (Alas, 1900: 164). Cuerpo, deseo y escritura se encuentran sugerentemente conectados en La Regenta. Los deseos perturbadores de índole sexual producen así una escritura en el cuerpo de los personajes ${ }^{16}$.

La novela de Leopoldo Alas, verdadero cuerpo saturado de sexo, construye una sociedad dominada por las "inclinaciones de la carne", por el "gusano maldito, del amor de los sentidos". La "fuerza anónima" e indestructible que homogeneiza en el vicio a los habitantes de Vetusta, incluida Ana Ozores, es el placer perverso. El escandaloso secreto de la sociedad decimonónica que Alas pareciera intentar ficcionalizar en La Regenta es, pues, la proliferación del placer perverso, a la vez que el fracaso de los poderes normalizadores y los dispositivos sociales que buscan controlar la emergencia de los "pinchazos de la carne".

\section{REFERENCIAS}

Alas, Leopoldo (Clarín). (1900). La Regenta. (2 tomos). Madrid: Librería de Fernando Fé.

. (1998). Sinfonía de dos novelas. Su único hijo. (Edición de Francisco Muñoz Marquina). Madrid: Ediciones Akal.

Bajtin, Mijail. (1990). La cultura popular en la Edad Media y en el Renacimiento. El contexto de François Rabelais. Madrid: Alianza Editorial.

${ }^{16}$ Los desvanecimientos de Bonifacio Reyes, en Su único hijo, parecieran apuntar hacia la misma revelación novelesca:

La Gorgheggi miró en rededor, se aseguró de que no había testigos, le brillaron los ojos con el fuego de una lujuria espiritual, alambicada, y, cogiendo entre sus manos finas y muy blancas la cabeza hermosa de aquel Apolo bonachón y romántico, algo envejecido por los dolores de una vida prosaica, de tormentos humillantes, le hizo apoyar la frente sobre el propio seno, contra el cual apretó con vehemencia al pobre enamorado; después, le buscó los labios con los suyos temblorosos...

- Un baccio, un baccio -murmuraba ella gritando con voz baja, apasionada. Y entre los sueños de una voluptuosidad ciega y loca, la veía Bonifacio casi desvanecido; después no oyó ni sintió nada, porque cayó redondo, entre convulsiones. (Alas 1998: 115). 
Beser, Sergio. (1982). Clarin y "La Regenta". Barcelona: Ariel.

Bobes Naves, María del Carmen. (1993). Teoría general de la novela. Semiología de "La Regenta". Madrid: Editorial Gredos.

Botrel, Jean-François. (1992). Alquimia y saturación del erotismo en La Regenta. En Díaz-Diocaretz, Myriam y Zavala, M., Discurso erótico y discurso transgresor en la cultura peninsular siglos XI al XX (pp. 109-128). Madrid: Teuro.

Bunge, C.O. (1903). La educación de los degenerados. Teoría de la educación. Madrid: Daniel Jorro Editor.

Coletes Blanco, Agustín. (2002). La huella inglesa en Clarín. En Agustín Coletes Blanco (ed.), Clarín, visto en su centenario (1901-2001) (pp. 3753) Oviedo: Real Instituto de Estudios Asturianos.

Deleuze, G. y Guattari, F. (1995). El anti Edipo. Capitalismo y esquizofrenia. Barcelona: Ediciones Paidós.

Faúndez V., Edson. (2010). Mimesis y deseo en la novela realista decimonónica: La Regenta de Leopoldo Alas, "Clarín” (Primera Parte). Acta Literaria, 40, 109-132.

. (2012a). Realismo e indeterminación (Aproximación teórico-crítica). El caso de La Regenta de Leopoldo Alas, "Clarín". Atenea, 505: 103-120.

. (2012b). La Regenta: Literatura y mal. En Edson Faúndez V. y Óscar Lermanda (eds.), El laberinto y el hilo. Homenaje a Gilberto Triviños (pp. 297-323). Concepción: Editorial Universidad de Concepción.

Foucault, Michel. (2000). Los anormales. Buenos Aires: Fondo de Cultura Económica.

(2007). Historia de la sexualidad. Vol. 1. La voluntad de saber. México D. F.: Fondo de Cultura Económica.

Girard, René. (1963). Mentira romántica y verdad novelesca. Caracas: Universidad Central de Venezuela.

Gullón, Ricardo. (1954). Aspectos de Clarín. En Archivum Tomo II (pp. 161-187). Universidad de Oviedo.

Kronik, John. (1987). El beso del sapo: configuraciones grotescas en $\mathrm{La}$ Regenta. En "Clarín” y La Regenta en su tiempo. Actas del Simposio Internacional (pp. 517-524). Oviedo: Universidad de Oviedo.

Marañón, Gregorio. (1958). Amiel. Un estudio sobre la timidez. Madrid: Espasa-Calpe.

Nimetz, Michael. (1971). Eros e Iglesia en la vetusta de Clarín. Trad. Ana María Alfaro-Alexander. Modern Language Notes, LXXXVI, 242-253.

Núnez Puente, Sonia. (2001). Ellas se aburren. Ennui e imagen femenina en 
"La Regenta" y la novela europea de la segunda mitad del XIX. Alicante: Universidad de Alicante.

Pardo Bazán, Emilia. (1887). La madre naturaleza, 2a parte de Los Pazos de Ulloa. Barcelona: Daniel Cortezo y Compañía.

Rutherford, John. (1988). La Regenta y el lector cómplice. Murcia: Universidad de Navarra.

Vázquez García, Francisco y Moreno Mengíbar, Andrés. (1997). Sexo y razón. Una genealogía de la moral sexual en España (siglos XVI-XX). Madrid: Akal Ediciones.

Vilanova, Antonio. (2001). Nueva lectura de "La Regenta" de Clarín. Madrid: Anagrama.

Zamora Juárez, Andrés. (1999). El doble silencio del Eunuco. Poéticas sexuales de la novela según Clarín. Madrid: Editorial Fundamentos. 